\title{
O belo, o feio e o abjeto nos corpos femininos
}

Berenice Bento (https://orcid.org/0000-0001-5839-0097)'

Departamento de Sociologia, Universidade de Brasília (UnB), Brasília, DF, Brasil
Recebido: 21.11 .19

Aprovado: 11.02 .21
Resumo: O projeto social hegemônico para os corpos generificados assenta-se na suposição de que existe uma relação de continuidade entre a genitália (vagina/pênis), o corpo inteiro (mulher/ homem) e as práticas generificadas (feminilidades/masculinidades). Esta linha de continuidade marcaria o que Judith Butler irá chamar de "gêneros inteligíveis". A hipótese deste artigo é que a noção que ameaça o reconhecimento de um corpo como pertencente a um determinado gênero não é a feiura. Beleza e feiura seriam gradações hierarquizadas da leitura sobre os corpos generificados inteligíveis. São os corpos das travestis, das pessoas trans, transgênero que expressariam o lado da negação, da abjeção e que estariam fora mesmo das hierarquias de beleza. As categorias centrais de análise serão abjeção e gênero E o objetivo será discutir as categorias belo, feio e abjeto nos femininos relacionando-as às noções de performance de gênero, paródia, próteses identitárias e relações de poder.

Palavras-chave: Belo. Feio. Abjeto. Feminino. Travesti.

\section{The beautiful, the ugly and the abject in female bodies}

Abstract: The hegemonic social project for the gendered bodies is based on the assumption that there is a continuity relationship between the genitalia (vagina / penis), the whole body (woman / man) and the gendered practices (femininities / masculinities). This continuity line would mark what Judith Butler will call "intelligible genres". The article hypothesis is that a notion that threatens the recognition of a body as belonging to a certain gender is not ugliness. Beauty and ugliness would be hierarchical gradations of reading about intelligible bodies. It is the bodies of transvestites, transgender people, transgender people who would express the side of denial, abjection and who would even be outside the hierarchies of beauty. The analysis categories will be abjection and gender. And the objective will be to discuss how beautiful, ugly and abject categories in women relate them to the notions of gender performance, parody, prosthetic identities, and power relations.

Keywords: Beautiful. Ugly. Abject. Feminine. Transvestite.

\section{Introdução}

$\square$ avid Hume (2000), em uma perspectiva subjetivista, irá potencializar aquele dito popular de que gosto não se discute. Segundo ele, cada pessoa deveria se contentar com seu sentimento sem desejar controlar o dos outros. Seria inútil estabelecer ou definir uma beleza real, ou uma deformidade real. Ao contrário, sugiro que gosto individual se discute, porque é resultado de múltiplos
I. Berenice Bento é professora associada do Departamento de Sociologia da Universidade de Brasília, UnB, Brasília, DF, Brasil.

<berenice.bento1@ gmail.com> 
1. Para uma discussão sobre a produção do gosto, ver Pierre Bourdieu (1983).

\section{Para esta}

discussão sugiro os textos de Jorge Leite Júnior (2011) principalmente a genealogia que o autor faz sobre a passagem das noções do hermafrodita, figura que trazia no corpo expressões do hibridismo, para o hermafrodita psíquico, como a sexologia do século XIX irá considerar os sujeitos que afirmavam viver em corpos equivocados. $\mathrm{O}$ autor também tem uma considerável produção sobre a categoria "monstro", "monstruosidade". A noção de "erro da natureza" irá encontrar na modernidade uma personagem, $\mathrm{o}$ médico, que irá encarnar a vontade de Deus e fará os ajustes necessários para que tudo volte a ter a verdadeira ordem natural. Os erros da natureza (expresso nas deformidades físicas) seriam os próprios estigmas que marcariam os corpos. determinantes. Não são os sujeitos isolados que, idiossincraticamente, irão distribuir elogios e recusas às formas, principalmente às corpóreas ${ }^{1}$. A interpelação "Que feio!" é uma citação, uma polifonia que antecede a cena e ao próprio sujeito da interpelação.

Aquilo que se supõe ser o que singulariza os sujeitos, o gosto pessoal, está amarrado a uma cadeia de sentidos construído historicamente que antecede a minha existência. As lutas políticas por emancipação e reconhecimento também são lutas contra determinadas estéticas da existência. Não foi exatamente isso que o movimento negro fez e segue fazendo quando afirma que "black is beautiful"? E nesta insígnia de luta está algo mais do que uma agenda política objetiva. Sua enunciação nos desloca para a tríade reconhecimento/luta por reconhecimento/desejo, nos termos proposto por Axel Honneth (2003). Um dos efeitos da luta por reconhecimento é o deslocamento de termos, a criação de novas categorias de inteligibilidade e o esvaziamento de outros.

Karl Marx (apud Eco, 2015a) também discutirá a relação entre beleza/feiura, mas numa perspectiva oposta à de Hume. Ao discordar de uma visão individualista, dirá que o dinheiro, com seu dom mágico e absoluto, consegue transformar o feio em belo. Para ele, aquilo que sou e o que eu posso, não são efetivamente determinados por mim, como uma qualidade inerente do meu ser, mas por condições externas: o quanto de dinheiro tenho na carteira. Mas esta visão materialista desconsidera que as estéticas corporais estão relacionadas a concepções morais. A quantidade de dinheiro que alguém possui não será suficiente para apagar as marcar nos corpos construídos como inferiores. A ascensão social não tem a capacidade de apagar as marcas dos corpos (negro, índio, travesti).

A relação entre belo/bom, feio/ruim é um dos eixos centrais da obra do filósofo hegeliano alemão Karl Rosenkrantz (apud Eco, 2015b: 138, 154, 256, 263, 312; Ferrer, 2017). Cesare Lombroso (2013) fez uma aproximação com as teses de Rosenkrantz ao estabelecer a relação entre criminoso nato e fisionomia. Para ele, há uma relação entre características físicas (consideradas feias) e moralidade.

Não é objetivo deste artigo fazer uma discussão sobre a relação entre moral e feiura/ beleza, tampouco sobre o vínculo entre feiura/maldade e beleza/bondade. Pode-se, contudo, inferir que a estética seja uma das chaves explicativas para compreender a constituição das noções de raça, elemento estruturante da biopolítica (Foucault, 1999) nos Estados modernos. A escravidão, experiência história determinante para explicar quem somos nós, tem na relação entre corpos negros, feiura, corpos sem alma e degenerescência moral elementos que irão justificar sua existência². Noções 
hegemônicas e dissidentes de estética são formas de distribuir os corpos em posições hierárquicas que visam organizar e disciplinar o desejo. Conforme tentarei apontar, parte considerável daquilo se nomeia como "feio" seria mais bem compreendido se acionássemos um terceiro termo: abjeção, principalmente quando transitamos no campo das experiências históricas desumanizadoras.

As noções de belo e feio que nos atravessam são atos políticos e têm efeitos no mundo da vida. No entanto, não estou convencida de que o feio seja a negação do belo. Será que qualquer feio estaria fora do mapa social? Conforme tentarei apontar, há níveis diferenciados de feiura dentro do feio e de beleza dentro do belo. Trata-se, portanto, de fugir de um campo analítico binário. Daí a importância da noção de abjeção para operar a ruptura dos binarismos analíticos referente às estéticas. O objetivo deste artigo será propor uma quebra nesta linha de continuidade (belo-feio) ao sugerir que a falta de inteligibilidade e, portanto, não reconhecimento, não cabe nas noções de "feiura", mas de abjeção. Qual seria o "feminino" abjeto? Esta será a pergunta-guia deste texto. Esta discussão será realizada em três momentos: i. Belo é feio, feio é belo; ii. Beleza abjeta? iii. Corpos não humanos: da abjeção ao transfeminicídio.

\section{Belo é feio, feio é belo!}

Umberto Eco dedicou dois grandes volumes à história da beleza e da feiura. Os livros intercalam textos dele mesmo, citações de filósofos e de escritores de outras áreas do conhecimento com centenas de reproduções fotográficas de obras de arte. O autor irá introduzir seus livros movido pelo espírito relativista. Nos dirá: "Os conceitos de belo e de feio são relativos aos vários períodos históricos ou às várias culturas" (Eco, 2015b: 10). Ainda: "Para um ocidental, uma máscara ritual africana poderia parecer horripilante - enquanto para o nativo poderia representar uma divindade benévola" (Eco, 2015b: 10).

Se a definição de belo e feio estão prenhes de história e significados culturais, este relativismo desaparece quando se pensa o conteúdo mesmo do que seja belo e feio. E como se define o feio e o belo? Segundo Eco, "na maioria das vezes, o feio era definido em oposição ao belo e quase não se encontram tratados mais extensos consagrados ao tema, mas apenas menções parentéticas e marginais" (Eco, 2015b: 9).

Eco recupera a ideia tradicional de que o feio é o contrário do belo. Analisa o feio da natureza, o feio espiritual, o feio na arte, a ausência de forma, a assimetria, a desarmonia, o vil, o banal, o morto e o vazio, o demoníaco. Não teríamos aqui um problema conceitual? Como é possível construir um conceito por um conjunto 
de adjetivos opositivos? Um conceito tautológico não seria a própria negação do conceito?

Eco continua a discutir belo como oposto do feio. Segundo ele, "consideramos o bonito, gracioso, prazenteiro, atraente, admirável [...] o feio, aquilo que é repelente, horrendo, asqueroso, desagradável, grotesco" (Eco,2015b: 19). O filósofo aciona um corpo de adjetivo para "definir o feio":

abominável, vomitante, odioso, indecente, imundo, sujo, obsceno, repugnante, assustador, abjeto, monstruoso, revoltante, repulsivo, desgostante, aflitivo, nauseante, fétido, apavorante, ignóbil, desgracioso, desprezível, pesado, indecente, deformado, disforme, desfigurado (Eco, 2015b: 19).

Aqui localiza-se o meu problema. Dizer que algo é disforme seria o mesmo que considerá-lo repulsivo ou abjeto? Não teria aqui níveis diferenciados de leitura possível das formas, principalmente dos corpos humanos? Estes níveis diferenciados não irão ter efeitos diferenciados no mundo da vida, nas estratificações e relações sociais?

Posição contrária parece ter as bruxas de Macbeth quando gritam: "Belo é feio, feio é belo!" (Shakespeare, 1989). O belo contém o feio. O feio contém o belo. Estão em relação, em linha de continuidade; são, portanto, simétricos e não assimétricos e fazem parte de um todo inseparável. Voltarei a esta discussão.

Todas as feiuras são iguais? Segundo Kant (1984), "somente uma espécie de feiura não pode ser representada conforme a natureza sem arruinar qualquer deleite estético e, portanto, a Beleza artística: a saber, aquela que desperta nojo". Assim, aquilo que no mundo da vida não tem linguagem, mas reação orgânica (nojo), seria também uma impossibilidade de representação. É possível vida fora dos marcos da representação, fora da linguagem? Se alguma coisa me provoca repulsa na vida real e se ao imaginá-la representada - seja em que arte for - a repulsa continuar, esta coisa não pode ser representada, ou seja, não pode estar presente na sua ausência, não pode, portanto, existir. Assim, diferente de Aristóteles, que defendia ser possível realizar o belo imitando com mestria aquilo que é repelente, Kant dirá que, no mundo da representação há limites e impossibilidades em fazer um objeto coisa feia tornar-se bela.

Se existe o "feio em si", há também o "belo em si", aquele que não precisaria de conceito, ou seja, de linguagem. A cultura seria dispensada para despertar em mim a admiração sem nenhum desejo de posse. Por exemplo, a beleza de uma flor. No 
entanto, quando eu digo "flor" já estou acionando um conceito. Estas sensações universais, regulares, não existam fora do mundo conceitual.

Depois desta rápida aproximação aos conceitos de belo e feio, discutirei o programa televisivo "Casos de Família". E aqui o objetivo será verificar se as noções de feio e belo, como atributos de substâncias distintas, se sustentam no que se refere aos propósitos deste artigo: pensar a questão estética vinculada aos femininos.

\section{Beleza abjeta?}

Gostaria de convidar o/a leitor/a a catar em suas memórias algum programa de auditório de televisão que tenham visto a presença de travestis e/ou mulheres trans. Vou descrever um dos muitos episódios de "Casos de Família", programa vespertino do $\mathrm{SBT}^{3}$.

A apresentadora do programa propõe um jogo de adivinhação. Vários homens estão sentados no palco. Ela diz: vocês terão que adivinhar quem é travesti e quem é mulher.

Alguns homens estufam o peito e dizem: eu jamais iria confundir uma mulher com um travesti.

Inicia-se o desfile.

As mulheres usavam uma pequena faixa na garganta para esconder um suposto pomo de adão. Depois, todas ficaram em pé, uma ao lado da outra e começaram a escutar as adivinhações dos homens.

3. "Casos de Família" é um programa de televisão no formato talk show, exibido pelo canal SBT, desde 2004, diariamente. A estrutura do programa fundamenta-se na espetacularização de conflitos, principalmente familiares, interpessoais (Disponível em: $<$ https://www. youtube.com/ watch?v= 4VAB4P8Ch1g>).

Agora, diante daqueles corpos exuberantes, eles já não estavam tão seguros como minutos antes. Nervosismo, gagueira e olhares aflitos estavam estampados em seus rostos. Pareciam olhares de cachorro perdido do dono.

Era possível perceber por suas performances masculinas que outra prova estava sendo realizada invisivelmente. Se eu errar, vão dizer que eu não sou homem. Estava em jogo também suas masculinidades. Mulher ou travesti? E as apostas começaram. A apresentadora provocava: tem certeza de que é uma mulher? O homem dizia "sim", mas sua cabeça dizia não. A confusão está montada.

A apresentadora, depois de ouvir os homens, perguntava para cada uma individualmente: você é travesti ou mulher? 
Uma das convidadas pediu para falar: "Homens, vocês não conhecem mulheres. Acho que todos vocês são gays!" A grande maioria dos homens, sem muita segurança, afirmou que ela era "um" travesti. Ela não perdoou. Anunciou o que eles tanto temiam.

Todas as fronteiras entre os femininos pareciam borradas, mas logo a ordem foi estabelecida quando cada uma revelou o segredo que transformou a palavra em ato criador de realidades (Austin, 1990): "sou mulher" ou "sou travesti".

A revelação de que aquela exuberância de mulher "não passava de um homem" produziu bocas abertas, certos silêncios e gritos da plateia. E qual a certeza que temos que uma travesti não disse que era mulher?

Aqueles corpos magros, esbeltos, seios duros, pernas torneadas, cabelos penteados, peles cuidadas, exibiam certos modos e modas de um feminino hegemônico. Eram bonitas. Apenas uma palavra - travesti - redefiniu completamente a avaliação de belo daqueles corpos. De olhares ávidos e gulosos, os homens passaram a retorcer suas caras. Eram fisionomias de nojo.

Estamos diante de um campo de afetação onde a oposição belo e feio não é suficiente para nos ajudar a entender esta mudança de registro da expressão do desejo. Antes, eu devoraria, comeria, pegaria. Agora, eu não consigo nem segurar meu olhar. O nojo é anunciado. A falta de gramática, de texto, enfim, a impossibilidade compreensiva preenche o ambiente. Um corpo, tão feminino, tão belo e... tão abjeto. Estamos, nos termos do Kant, diante do irrepresentável.

A internet está repleta de casos como este. Há "flagras" de homem beijando muIheres e se deliciando. De repente, escuta-se um grito: $E$ um travesti - a reação imediata é uma conexão entre a fisionomia e o estômago.

No filme "Traídos pelo desejo", Fergus (um guerrilheiro do Exército Republicano Irlandês, IRA), diante do corpo nu de Dil descobre que ela era mulher trans. Em desespero, corre para banheiro e tranca a porte. Apenas escutamos o barulho do seu vômito. Na ausência de gramática, o discurso possível foi o vômito. Não tinha palavras, mas suas vísceras e líquidos estavam em conexão com as definições políticas, históricas e sociais de que a beleza feminina precisaria de um corpo-sexual, a vagina, para estabilizá-la e dotá-la de sentido. 


\section{Corpos não humanos: da abjeção ao transfeminicídio}

Concordo com Judith Butler (2003) quando afirma que não existe uma essência interior que é posta em evidência através dos atos. Se o corpo é plástico, manipulável, operável, transformável, o que irá estabilizá-lo na ordem dicotomizada dos gêneros é sua aparência de gênero. O sentido que se atribui às roupas e aos acessórios liga-se a um campo mais amplo de significados que extrapola a ideia de um "gosto pessoal", vinculando-se às normas de gênero que estabelecem determinadas formas de cobrir os corpos-sexuados.

O gênero só existe na prática e sua existência só se realiza mediante um conjunto de reiterações cujos conteúdos são frutos de interpretações sobre o masculino e o feminino. O ato de pôr uma roupa, escolher a cor, compor um estilo são ações que fazem o gênero, que visibilizam e posicionam os corpos-sexuados, os corpos em trânsito ou os corpos ambíguos, na ordem dicotomizada dos gêneros. Vestir-se é um dos atos performáticos mais carregados de significados para a construção das performances dos gêneros.

A força das normas sociais, especificamente às de gênero, oblitera o pensamento e não nos deixa ver o que está ali, diante de nós: a impossibilidade de se definir feminilidade a partir da genitália.

Então, o que é gênero? Se os gêneros não estão vinculados a uma essência e é da ordem das práticas, podemos pensar em pluralidades de performances femininas.

As mulheres com vagina fariam parte deste campo feminino, mas não são as únicas que podem reivindicar o reconhecimento feminino. Mas será que todos os femininos têm a mesma possibilidade de existência e de vida? Quais seriam as hierarquias internas ao feminino?

Os sujeitos constroem suas ações por suposições e expectativas, conforme apontou George Mead (apud Honneth, 2003). No caso do gênero, as suposições funcionam como se uma essência interior que marca a existência da mulher e do homem pudesse pôr-se a descoberto. Cada ato é uma tentativa de desvelamento dessa certeza, como se fosse "a natureza" falando em atos. Essa suposição gera um conjunto de expectativas fundamentalmente baseadas nas idealizações de uma "natureza perfeita", como é o exemplo do "instinto materno" ou do "homem naturalmente viril e forte". As expectativas, em articulação com as suposições, acabam produzindo, conforme sugeriu Butler, o fenômeno mesmo que antecipa, pois fazem com que os sujeitos ten- 
tem, em suas práticas, reproduzir modelos que se supõem como verdadeiros para seu gênero ou para o gênero com o qual se identificam, como é o caso dos/as transexuais.

A verdade dos gêneros, no entanto, não está na biologia dos corpos; estes, inclusive, devem ser observados como efeitos de um regime que não só regula mas cria as diferenças entre os gêneros. A experiência transexual destaca os gestos que dão visibilidade e estabelecem o gênero através de negociações e de interpretações, na prática, do que seja um homem e uma mulher. A aparente cópia não se explica em referência a uma origem. A própria ideia de origem perde o sentido e se passa a considerar a/o mulher/homem de verdade também como cópia, uma vez que tem de assumir o gênero da mesma forma: através da reiteração dos atos.

Uma derivação daqueles que analisam a experiência transexual como imitação das "mulheres/homens de verdade" está nos que os/as qualificam como reprodutores dos estereótipos. Tal afirmação reforça, por outros caminhos, a tese de que existe uma verdade única para os gêneros. Na aparência de uma crítica feminista, recupera-se o essencialismo por outros caminhos.

Este campo é marcado por posições de poder diferenciadas. Acredito que a polaridade belo/feio funcionaria atualmente para se pensar as diferenças valorativas entre as corporalidades das mulheres brancas e negras.

Se digo "atualmente" é porque há pouco tempo as pessoas negras não eram consideradas somente feias. Feia podia ser a amiga da sinhazinha, o primo do sinhozinho, a esposa do senhor escravocrata. A negra e o negro anunciavam uma corporalidade que não era passível de ser representada nesta linha de continuidade (belo/ feio). Eram corpos abjetos. Mas a abjeção, embora esteja em níveis estruturais e estruturantes das relações sociais e das subjetividades também é histórica. A luta política das pessoas negras, como bem revela o lema "Black is beautiful", fez o olhar se mover.

Então, voltando à minha proposta de pensar as hierarquias internas ao feminino, diria que há vários outros níveis: gorda/magra, nordestina/sulista, atrasada/moderna, puta/santa. Mas ainda nos movemos aqui ao nível da relação feio/belo. No entanto, há outro nível de hierarquia que é posto em cena, por exemplo, no programa "Casos de Família". O feminino performático das travestis não entra nessa relação comparativa e de continuidade feio/belo.

Da mesma forma que as lutas movidas em torno da "raça", por exemplo o fim da escravidão, anunciavam a precariedade da noção de humanidade, o que os corpos 
trans e travestis põe em cena são as limitações de uma concepção de humanidade dividida em homens-pênis e mulheres-vagina.

Os sucessivos genocídios que atravessam a história nos dizem: nem todas as pessoas podem usufruir do pertencimento a esta coisa maravilhosa chamada "humanidade". Ainda estamos às voltas, em nossas pesquisas, tentando entender os mecanismos de poder que inventaram a "humanidade".

Esvaziar o Outro, o inimigo, de qualquer atributo de humanidade tem sido uma estratégia discursiva de guerra largamente utilizada. Para Humberto Eco (2015b) este seria o segredo do porquê alguns são considerados feios: o que esta leitura estética esconde é o desejo de poder.

Como não lembrar a controvérsia de Valladolid (Wallestein, 2007)? Esta cidade espanhola assistiu ao intenso debate, em 1550, entre Juan Ginés de Sepúlveda e Bartolomeu de Las Casas. Sepúlveda alegava que era lícito e justo que os espanhóis escravizassem os índios porque eles eram bárbaros e, portanto, naturalmente escravos; de Las Casas respondia que não era possível aplicar aos índios o adjetivo de "bárbaros" sem antes distinguir as diversas classes de barbárie. O domínio sobre novos territórios, desejado pela Espanha, se daria pela força militar, e por argumentos jurídicos, filosóficos e teológicos que justificaram suas ações.

Quando discutimos quais os seres merecem reconhecimento humano e que, portanto, podem habitar o mundo humano, precisamos suspender os sentidos naturalizantes e naturalizados que são conferidos às próprias noções de "humano" e "humanidade". Estas não são categorias analíticas e políticas autoevidentes.

Assim, ao focar meu olhar sobre a relação entre belo/feio e abjeto estou mais interessada em entender quais corpos possuem determinadas materialidades e performances para adentrarem na categoria celebratória do que chamamos "humanidade". Ao longo da história, o que temos assistido são disputas ferozes e sangrentas em torno das compreensões do que seja humanidade. Neste caso, não se trata de Outro, aquele das alteridades, o diferente.

Seria possível afirmar que haja genocídio motivado por uma determinada concepção de gênero? Não seriam os assassinatos sem punição das pessoas trans uma expressão continuada da negação de humanidades destas identidades construídas hegemonicamente como abjetas? Eu não canso de me perguntar como é possível entender que estejamos vivendo numa época de extermínio diante de nós de um tipo de expressão do feminino - as múltiplas identidades trans - e que um silên- 
cio cúmplice de todas as instituições sociais parece desejar que o transfeminicídio (nome que sugiro para este tipo específico de genocídio) não cesse. Assim, diria que a binariedade belo/feio não é suficiente para entender o funcionamento da máquina produtora de seres que não merecem viver.

Joseph Conrad (2008) no livro No coração das trevas relata a experiência pessoal no Congo. Através do protagonista - Charlie Marlow - ele narra seu testemunho dos abusos do poder colonial. Ali, o cheiro da principal mercadoria, o marfim, inundava o ar, atravessava as florestas, que era cortada pela crueldade dos funcionários belgas.

Bem, os senhores sabem isso era o pior... a suspeita de que não eram inumanos. Tal noção surgiu aos poucos. Eles urravam e pulavam, e giravam e faziam caretas horrendas; mas o que nos impressionava era, precisamente, a ideia de que eram humanos... tanto quanto nós... a ideia do nosso passado remoto parentesco com aquele alarido selvagem e ardente. Horrendo (2008: 74).

Entre tantos medos, qual fazia Marlow paralisar? Medo de qualquer identificação, de qualquer campo de intersecção com os nativos do Congo, seres de "corpos horripilantes". Eles eram os seres sem história, sem memória.

\section{Entre o abjeto e a objeto}

A abjeção (do latim, ab-jectio) significa jogar fora, excluir. Butler irá fazer uma aproximação com o conceito psicanalítica de foraclusão que funda o sujeito e sua sociabilidade mediante o repúdio de um significante primário que produz inconsciente ou, na teoria lacaniana, o registro do real. A noção de abjeção, ao contrário, designa uma condição degradada ou excluída dentro dos termos da sociabilidade. Em realidade, o foracluído (ou repudiado, dentro dos termos psicanalíticos) é precisamente o que não pode voltar a entrar no campo do social sem provocar a ameaça de psicose, quer dizer, de dissolução do sujeito mesmo. A sentença "prefiro morrer a fazer tal coisa" seria o fantasma dessa dissolução atuando no sujeito.

O que é o abjeto, como ele se constitui? A coletânea Poderes do horror. Ensaios sobre a abjeção, de Julia Kristeva, é uma referência nas pesquisas que acionam a categoria abjeção. Embora os ensaios sejam importantes para se pensar a constituição de subjetividades e corporalidades construídas na abjeção, não nos ajuda entender como, socialmente, o sujeito é localizado como abjeto e quais os efeitos políticos de uma existência construída fora do humano. Há questões interessantes apontadas pela psicanalista. Quando ela afirma que "essencialmente diferente da 'inquietante 
estranheza', a abjeção se constrói sobre o não reconhecimento de seus próximos: nada Ihe é familiar, nem mesmo uma sombra de recordação" (Kristeva, 1980: 19). Mas como o sujeita se abjeta? Como ele se vê como abjeto? Kristeva dirá:

\begin{abstract}
A abjeção de si será a forma culminante dessa experiência do sujeito ao qual é revelado que todos os seus objetos repousam somente sobre a perda inaugural fundante de seu próprio ser... Nada melhor do que a abjeção de si para demonstrar que toda abjeção é de fato reconhecimento da falta fundadora de todo ser, sentido, linguagem, desejo (Kristeva, 1980: 16).
\end{abstract}

A autora explicará a estrutura psíquica do sujeito abjetado na relação mãe (fundamentalmente) e pai. O lugar explicativo da estrutura consciente/inconsciente do abjeto coincidirá, para a autora, com o perverso. Kristeva (1980: 14) dirá que "o abjeto é perverso porque não abandona nem assume um interdito, uma regra, uma lei; mas distorce-os, extravia-os, corrompe-os; serve-se deles, usa-os, para melhor negá-los".

Ao final, a psicanalista irá equalizar a abjeção a "uma espécie de crise narcisística". Os sentidos conferidos à abjeção na produção do sujeito giram em torno da família. Nenhuma referência às condições históricas e às normas sociais é acionada para explicar como se produz a abjeção e quais são os seus efeitos na vida social dos sujeitos, seja na estruturação do reconhecimento recíproco ou na luta por reconhecimento. Estamos diante de uma explicação focada no indivíduo, ou exclusivamente na relação deste com um microuniverso: a família, como fonte explicativa seja da organização (ou desorganização) das subjetividades em suas dimensões consciente e inconsciente e não as insere em configurações discursivas mais amplas.

A visão universalista da autora sobre abjeção termina por reproduzir uma concepção colonialista. Kristeva (1980: 23) dirá que a "abjeção aparece como um rito de imundície e da contaminação no paganismo que acompanha as sociedades em que predomina ou sobrevive o poder matrilinear". De que sociedade e tempo ela está falando? Quais as pesquisas que a autora cita para fazer tais afirmações? A noção de abjeção de Kristeva nos serve muito pouco, principalmente quando quero entender não exclusivamente a produção subjetiva, mas qual o espaço social que existe para os sujeitos que estão fora das normas de gênero e quais são as normas estéticas que conferem sentido a determinadas corporalidades. Outra dimensão para se pensar em relação à abjeção é a compreensão dos efeitos da autopercepção como abjeto, trazendo para suas entranhas a responsabilidade de uma vida impossível. 
A politização do abjeto será uma das marcas do pensamento de Judith Butler. Diz a autora,

O sujeito se constitui através da força de exclusão e abjeção, uma força que produz um exterior constitutivo do sujeito, um exterior abjeto que, depois de tudo, é interior ao sujeito como seu próprio repúdio fundamental. A formação de um sujeito exige uma identificação com o fantasma normativo do "sexo" e esta identificação se dá através de um repúdio que produz um campo de abjeção, um repúdio sem o qual o sujeito não pode emergir (Butler, 1980: 20).

A importância que Butler confere ao abjeto para a formação do sujeito, no entanto, não lhe basta. A filósofa irá analisar cenas políticas nas quais sujeitos lutam para entrar na esfera ontológica e oferecer respostas aos poderes instituídos. Afirmar que os seres abjetos estão fora do definido como humanos não seria uma contradição? A não aceitação de certos tipos de corpos, manifesta-se na esfera política.

O que significa lutar pelo reconhecimento jurídico/legal das identidades de gênero trans? Aqui nos movemos em territórios de disputas ontológicas em que a tríade belo/feio/abjeto será acionado pelos controladores das fronteiras do reconhecido como humano. Uma decisão de um juiz, por exemplo, que nega a demanda de uma mulher trans pela mudança dos documentos é um ato de controle das fronteiras da ontologia. E a mulher trans ao entrar na cena pública e empreender a luta por reconhecimento está produzindo ruídos e talvez mesmo inaugurando um novo domínio ontológico. É nestas lutas por reconhecimento que se nota o deslocamento da abjeção. Daí o caráter histórico, político e social da categoria abjeção.

Para pensar a materialidade dos corpos e a formação subjetiva há movimentos de atração (identificação) e repulsa (negação). Quando nos referimos às inteligibilidades dos corpos, movemo-nos no âmbito do reconhecimento recíproco. Parece-me que parte considerável do que Butler escreveu sobre inteligibilidade pode ser lido nos marcos da produção do sujeito hegeliano, ou seja, nos marcos da relacionalidade ética que se efetiva na busca reiterada de satisfação das expectativas do desejo do outro. Há, contudo, a produção simultânea de uma esfera de seres abjetos, dos não sujeitos, que constitui o exterior dos sujeitos, designado por Butler como zonas "invisíveis", inabitáveis da vida social, mas que estão densamente povoadas por quem não goza da hierarquia dos sujeitos. A condição de viver sob o signo do invisível é fundamental para definir a esfera dos sujeitos. Esta zona inabitável será o limite que definirá o terreno do sujeito, constituirá este lugar de identificações negadas e em virtude das quais o terreno do sujeito circunscreverá sua própria pretensão de autonomia e a vida. 
Como é que alguns tipos de sujeitos reivindicam ontologia, como é que eles contam ou se qualificam como reais? Nesse caso, estamos falando sobre a distribuição de efeitos ontológicos, que é um instrumento de poder, instrumentalizado para fins de hierarquia e subordinação e também com vistas à exclusão e à produção de domínios do inimaginável.

A capacidade heurística e política da noção de abjeção não se limita ao sexo e ao gênero, campos que a utilizam mais largamente para discutir as dissidências. Relaciona-se a todo tipo de corpos cujas vidas não são consideradas vidas e cuja materialidade é entendida como não importante. Historicamente, construíram-se figuras abjetas exemplares: as bruxas, os hereges, os bárbaros. Um dos elementos estruturantes da produção dos sujeitos abjetos é a negação da singularidade. Assim, basta eu falar "travesti" que o termo nomeia e qualifica todas as pessoas que vivem a travestilidade. Não há diferença, não há biografia. A retórica universalista olha para os corpos como uma anátema sem distinção.

Ao deslocar os casos possíveis de serem analisados como expressões de sujeitos abjetos - e não me limitando à relação entre belo/feio/abjeto nos corpos femininos -, objetivei fugir de uma possível fixação e limitação do alcance da noção de abjeção. Os exemplos que citei tampouco esgotam a definição de abjeção. Os exemplos podem transformar-se, conforme apontou Butler (2002) em referências normativas do significado de abjeto e ao fazê-lo. Pode-se estar contribuindo para transformar determinada população como paradigmática da abjeção. Ao fazê-lo, seus efeitos podem ser a produção de hierarquia entre as identidades abjetas - e, portanto, do sofrimento - e a invisibilização de outras abjeções.

Então, não é que o impensável - aquilo que não pode ser vivido ou compreendido não tenha uma vida discursiva; o impensável certamente a tem. Mas ele vive dentro do discurso como a figura absolutamente não questionada, a figura indistinta e sem conteúdo de algo que ainda não se tornou real.

Ao considerar o que discuti até aqui, é possível inferir que os corpos abjetados não despertam desejo e que, portanto, o desejo por corpos não binários seria um delimitador da fronteira entre o que se aceita como humanamente possível e aquilo que é negado. E daí poder-se-ia derivar conclusões acerca do desejo.

Ao ler as pesquisas de Larissa Pelúcio (2009), pode-se inferir que desejar não é suficiente para transpor os muros invisíveis da alcova e sair de mãos dadas na rua com uma travesti. A relação entre desejo e abjeção é escorregadia. Basta olharmos os sites pornôs para vermos a quantidade de páginas que oferecem os serviços das 
trabalhadoras sexuais travestis e transexuais. Por outro lado, são inúmeros os relatos de travesti que relatam agressões e tentativas de homicídios perpetrados, muitas vezes, por seus clientes. Portanto, em termos de transformação do lugar que socialmente se reserva para os gêneros não inteligíveis, não seria necessário pensar apenas a relação desejo/abjeção, é necessário vinculá-la ao mundo da política?

\section{Conclusão}

Ao acionar a categoria abjeção para contrapor-me à díade belo-feio, tentei apontar como este terceiro termo nos revela outra posição ontológica para as corporalidades e as subjetividades que estão fora do reconhecimento recíproco. Quando citei o programa "Casos de Famílias" foi para apontar os limites desta díade. Talvez a força da categoria abjeção esteja em apontar que:

i. pensar a constituição dos sujeitos a partir de díades, nos termos dialéticos do senhor-escravo, termina por reintroduzir as invisibilidades de sujeitos que não contam, não importam, para a estruturação da vida social. A ontologia é um domínio, um território controlado e regulamentado por uma multiplicidade de discursos.

ii. Não há ilusão de que o compartilhamento de corporalidades "humanas" seja suficiente para se produzir reconhecimento. Os corpos em suas aparências de humanos não os qualificam imediatamente para serem reconhecidos como humanos e, portanto, para estabelecerem relacionalidade ética e habitarem os domínios ontológicos. Aqui, a luta por reconhecimento difere-se daqueles corpos que já estão incluídos na categoria de humanidade e que aparecem na hierarquia social em posições inferiores. Hierarquizar é pôr em relação e em comparação. As corporalidades abjetas, ao contrário, estão fora desta hierarquia.

\section{Referências}

ARISTÓTELES. Poética. Porto Alegre: Globo, 1966.

AUSTIN, J. L. Quando dizer é fazer: palavras e ação. Porto Alegre: Artes Médicas, 1990.

BENTO, Berenice. A reinvenção dos corpos: sexualidade e gênero na experiência transexual. 3. ed. Salvador: Editora Devires, 2017. 
BOURDIEU, Pierre. A distinção: crítica social do julgamento. São Paulo: Editora USP, 2007.

Gostos de classe e estilos de vida. In: ORTIZ, R. (Org.) Pierre Bourdieu: sociologia. São Paulo: Ática, 1983.

BUTLER, Judith. Problemas de gênero - feminismo e subversão de identidade. Rio de Janeiro: Civilização Brasileira, 2003.

. Como os corpos se tornam matéria: entrevista com Judith Butler. Revista Estudos Feministas, n. 157, 2002.

CONRAD, J. No coração das trevas. São Paulo: Hedra, 2008.

ECO, Humberto (Org.). História da beleza. Rio de Janeiro; São Paulo: Record, 2015a. . História da feiura. Rio de Janeiro; São Paulo: Record, 2015b.

FERRER, Diogo. Sobre a estética do feio em Karl Rosenkranz e Christian Hermann Weisse. International Journal of Phenomenology, Hermeneutics and Metaphysics, v. 1, n. 1, 2017. Disponível em: <http://e-revista.unioeste.br/index.php/aoristo/article/view/16529/11196>. Acessado em: 13 Dez. 2020.

FOUCAULT, Michel. Em defesa da sociedade. São Paulo: Martins Fontes, 1999.

GROSFOGUEL, Ramón. A estrutura do conhecimento nas universidades ocidentalizadas: racismo/sexismo epistêmico e os quatro genocídios/epistemicídios do longo século XVI. In: BERNARDINO-COSTA, Joaze; GROSFOGUEL, Ramon. Decolonialidade e perspectiva negra. Sociedade e Estado, v. 31, n. 1, Jan./Abr. 2016.

HUME, David. Ensaios morais, políticos e literários. São Paulo: Abril Cultural, 2000.

HONNETH, Axel. Luta pelo reconhecimento - para uma gramática moral dos conflitos sociais. São Paulo: Editora 34, 2003.

KANT, Immanuel. Crítica da capacidade de juízo. São Paulo: Abril Cultural, 1984.

KRISTEVA, Julie. Approche de l'abjection. In: Pouvoirs de l'horreur. Essai sur I'abjection, p. 7-27. Paris: Les Éditions du Seuil, 1980.

LEITE JUNIOR, Jorge. Nossos corpos também mudam: a invenção das categorias "travesti" e "transexual" no discurso cientifico. São Paulo: Annablume, 2011.

LOMBROSO, Cesare. O homem delinquente. São Paulo: Ícone, 2013. 
PELÚCIO, Larissa. Abjeção e desejo: uma etnografia travesti sobre o modelo preventivo de Aids. São Paulo: Annablume, 2009.

SANTOS, Leonel Ribeiro. Karl Rosenkranz e a confirmação do feio como categoria estética. In: SERRÃO, Adriana V. et alii (Org.). O feio para além do belo, p. 87-110. Lisboa: Centro de Filosofia da Universidade de Lisboa, 2012.

SHAKESPEARE, W. Macbeth. São Paulo: Brasiliense, 1989.

WALLESTEIN, Immanuel. Universalismo europeu. Retórica do poder. São Paulo: Boitempo, 2007. 